\title{
ARTICLE
}

\section{Ethics in environmental politics and sustainable use of the planet}

\author{
John Cairns, Jr.* \\ Department of Biology, 1020 Derring Hall, Virginia Polytechnic Institute and State University, Blacksburg, Virginia 24061, USA
}

\begin{abstract}
Environmental politics, especially regarding sustainable use of the planet, must be based on a shared set of ethical values. Although there is a fundamental conflict between ecological doctrine and human cultures, naturalistic assemblages of plants and animals can co-exist with human society in a mutualistic relationship. Numerous environmental practices of human society have ethical implications and are serious obstacles to the quest for sustainability. Continuing them will probably result in crossing one or more important ecological thresholds, which may result in new ecological conditions less favorable to human society than those that presently exist. Some of the probable conditions (e.g., global climate change) could be characterized as paradigm-shifting catastrophes. Motivational ethics may triumph initially, but consequential ethics may eventually emerge in environmental politics, which would then produce some interesting conditions in a sustainability context. Since humans have only one planet on which to experiment, speculation about possible future scenarios seems prudent, as does precautionary action to avoid undesirable outcomes.
\end{abstract}

KEY WORDS: Sustainability · Ethics · Biosphere $\cdot$ Life support system $\cdot$ Humanization of earth $\cdot$ Paradigm shifts

I have set before thee life and death, blessing and cursing: therefore choose life, that both thou and thy seed may live.

Deuteronomy 30:19

During nearly all the history of our species man has lived in association with large, often terrifying, but always exciting animals. Models of the survivors, toy elephants, giraffes and pandas, are an integral part of contemporary childhood. If all these animals became extinct, as is quite possible, are we sure that some irreparable harm to our psychological development would not be done?

G. Evelyn Hutchinson (1962, p. 74)

\section{ETHICAL CO-EXISTENCE}

The ethical obligation of human society to the biospheric life support system is easily stated. Human society benefits from natural capital and the services it pro-

*E-mail: jcairns@vt.edu vides, but gives little in return and is damaging the system in a variety of ways. Attempts to protect habitat (e.g., wetlands, tropical rain forests) encounter strong political resistence. However, even exemplary protection does not meet fully human society's ethical responsibility for the condition of the biospheric life support system. Human society must actively care for the health and ecological integrity of the system. As Dubos (1980) remarks:

'Since the humanization of Earth inevitably results in destruction of the wilderness and of many living species that depend on it, there is a fundamental conflict between ecological doctrine and human cultures, a conflict whose manifestations are most glaring in Greece'.

In my view, naturalistic assemblages of plants and animals can co-exist with human society in a mutualistic relationship. The quest for material wealth has impoverished the biosphere, and still over half the humans on the planet exist on the equivalent of a few US \$/day per capita. A society with automobile bumper stickers that claim 'He who dies with the most toys wins!' clearly needs to reexamine its ethics. 


\section{ETHICS IN SCIENCE AND SOCIETY}

Successful implementation of sustainability initiatives requires that human society have trust in both its leaders and its scientists. Trust requires both faith and some degree of understanding of how the interdependent web of life works (i.e., the ecological life support system of which humans are a part). In addition, environmental politics must be based on a shared set of values - an environmental ethos (Cairns 2001)! Human society is presently far from trusting the motives of those espousing sustainability. Bartlett (1997-98) notes that, at one end of the spectrum, the term sustainable is used with precision. In the middle of the spectrum, the term is simply added as a modifier to the names and titles of beneficial studies in efficiency, etc. that have been around for years. At the other end of the spectrum, the term is used as a placebo. In some cases, the term may be used mindlessly (or possibly with the intent to deceive) in order to shed a favorable light on continuing activities that may or may not be capable of continuing for long periods of time. In the United States, the term environmentalist has almost lost its meaning since persons who clear cut forests, build highways through natural systems, etc. now often claim this title.

Soulé (2001) states that a growing chorus of critics now believes that the popular sustainable development paradigm has done more harm to nature than good, having set back conservation by a decade or more, particularly in rainforest areas of the tropics. In contrast, Salafsky et al. (1993) believe that a process they refer to as sustainable exploitation generates local income without compromising biodiversity values. Sustainable exploitation includes such activities as bird watching and other wildlife viewing, local artisan production or value-added wood products, harvesting of natural products (e.g., Brazil nuts), and carefully managed safari hunting. However, Terborgh (1999) and Oates (1999) note the drastic decline in the creation of nature reserves and wildlife parks while many others have essentially ceased to exist. Brandon (1998) describes the problems with multiple-use biospheric reserves and notes that they are unlikely to succeed in preserving biodiversity unless users agree to: (1) different use levels in different zones and (2) the enforcement of sanctions against those breaking the rules. McDonell \& Vacarin (2000) espouse the participation of local people in such efforts, including both management and benefits.

\section{THE ETHICAL DILEMMA}

The ancient Greeks were an extraordinary culture as far back as $6^{\text {th }}$ century BC. Yet even during its modest beginnings, Greek philosophy touched on many veins of Western scientific thought (e.g., astronomy, law, political science, physics, psychology, medicine, etc.) without access to most of the implements on which modern science depends (e.g., electricity, computers, telescopes, microscopes, chemical analyses, etc.). Einstein once stated: 'I did not come to my understanding of the fundamental laws of the universe through my rational mind.' Einstein's seven years as a minor civil servant in the Swiss Patent Office afforded him many hours for thinking about the universal laws in a less superficial way than present hectic society permits. In The Republic, Plato inferred that learning was actually remembering and that humankind is born into some form of amnesia.

\section{PRACTICES OF HUMAN SOCIETY THAT REQUIRE HIGHER ETHICAL STANDARDS}

To perform any tasks sustainably implies practices that can continue indefinitely. However, the term development implies growth (i.e., economic development) of material goods or human artifacts to most people. In this context, the ideas of sustainable development on a finite planet is an oxymoron. Sustainable use, without abuse, can probably be carried out indefinitely and is, thus, more ethically defensible.

An illustrative list of practices of human society that have profound ethical implications follows:

1. advocating exponential growth on a finite planet;

2. displacing natural systems with anthropogenic artifacts (e.g., shopping malls) without seriously considering alternatives (e.g., neighborhood stores, Internet shopping);

3. not treating the biospheric life support system with the reverence that a system essential to life deserves

4. failing to recognize (or admit) that anything inherent in human nature is biologically based and, consequently, that humans have a kinship with other creatures;

5. exploiting the common grounds (e.g., air, oceans, public land, and water) so that benefits accrue to a few and the losses are borne by many

6. failing to recognize that individual "rights" (e.g. food, shelter, water) are based on natural capital and that each individual is a part of, not apart from, the interdependent web of life;

7. depriving both present and future generations of ecosystem services through destruction of natural capital;

8. dismissing rather than discussing the hazard cues that the environment provides, such as biotic 
impoverishment, endocrine disrupters, evidence of global warming;

9. dehumanizing oneself by ignoring that compassion for all humans and other creatures is essential to sustainable use of the planet;

10. downplaying sound scientific information, which is essential to sustainable use of the planet.

\section{THE TITANIC HUBRIS}

Films such as 'A Night to Remember' and other stories of the ill-fated steamship Titanic enthrall people long after the event. Even people not yet born when the ship sank are fascinated by the story. Individual dramas are a significant component, but the larger scale events are the ones that are haunting! Arguably, they do so because the events on the Steamship Titanic have remarkable similarity to present events on Spaceship Earth. The important components are:

1. an unshakable faith in the powers of technology to shield humankind from all sorts of natural forces;

2. a tendency to believe that human knowledge is sufficient to predict future events and allow time to be well prepared for them;

3. an extreme reluctance to change human behavior even when substantial evidence indicates it is no longer appropriate;

4. a slow and ineffective response to unexpected problems when precautionary action is needed.

The spatial and temporal scales for a sustainable planet far exceed those of the Titanic disaster, but the basic paradigms that influenced the outcome remain unchanged despite impressive technological advances and the emergence of the information age. Perhaps even more important are the many forms of exponential growth (economic, population, urban sprawl, loss of rainforests and other natural systems) that dramatically reduce the time to respond to trends and/or prevent ecological damage.

\section{CROSSING ONE OR MORE MAJOR ECOLOGICAL THRESHOLDS}

The Associated Press (2001a) has reported that bans on logging roads may be lifted under the new U.S. administration, and U.S. President Bush has told the U.S. Congress that he will not regulate carbon dioxide emissions from power plants because he does not believe the scientific evidence for the effects of anthropogenic greenhouse gases is robust (Associated Press 2001b). In addition, energy shortages in the United States indicate a high probability that supplies of energy will be sought more vigorously, even in envi- ronmentally sensitive areas. Also, U.S. Environmental Protection Agency chief Christine Todd Whitman is poised to relax a pollution standard involving reformulated gasoline (Wire Reports 2001). These considerations are important because the United States, with less than 300 million people of over 6 billion, uses approximately one quarter of the world's energy and is accounting for almost the same proportion of $\mathrm{CO}_{2}$ emissions (Ehrlich \& Ehrlich 2001). Furthermore, the same report indicates that, to reduce pressure on human life-support systems, the United States must set an example for other countries by establishing a population policy that halts rapid population growth $(13 \%$ since 1990) and by initiating a national dialog on curbing runaway consumption while increasing quality of life for Americans.

As if the bad news already given were not enough, Schettler et al. $(1999,2000)$ note that the intersection between environmental chemicals and child development has produced evidence of the effects of environmental chemicals on a number of important processes such as: developmental disabilities, including attention deficit/hyperactivity disorder; autism; and related neural developmental diseases, all of which affect millions of American children. Biotic impoverishment, the loss of biodiversity on the planet, is too well documented to require any references. Furthermore, the freshwater supply of the world is being mismanaged in a variety of ways (e.g., Postel 1999). These examples are just a few illustrations of adverse anthropogenic effects on both humans and their ecological life support system. Not only are these actions being tolerated, but governments are subsidizing them with tax monies (Myers with Kent 1998). As historian McNeill (2000) notes, humans have been reshaping the face of Earth for millennia, but the $20^{\text {th }}$ century witnessed rates of environmental transformations at a scale never before seen - the consequences of which remain uncertain. Human society is often slow to adapt when their behavior and practices seriously threaten their ecological life support system (e.g., Diamond 1994, 1997). As a consequence, it seems highly probable, arguably almost inevitable, that human society will push its ecological life support system past one or more crucial breakpoints or thresholds. Odum (2001) shares this view. The increased globalization of the economic system also increases the probability that both the spatial and temporal scales will be vastly increased over the historic examples already available in the collapse of civilizations through history over a variety of geographic areas. It is important to note that natural systems do not have the homeostatic mechanisms that result in physiological stability in humans and other creatures. A natural system pushed over a crucial breakpoint or threshold may not return to its predistur- 
bance condition or state, but rather to some new equilibrium condition which may or may not have existed in the past. With regard to the field of ecotoxicology, where these thresholds have been studied extensively, the problem is exceedingly complex (e.g., Cairns 1992). Several outcomes do seem highly probable: (1) the new ecological equilibrium conditions may not be as favorable to humans as the present ones; (2) invertebrates and disease-causing organisms have shown themselves remarkably adaptable in such areas as resistance to pesticides, antibiotics, and the like, and they are therefore likely to adapt to new conditions more rapidly than humans; and (3) as Cairns (1994) notes, human society and natural systems are coevolving and, while coevolution may appear beautiful in its final state, there are extremely harsh penalties exerted on those components or attributes that fail to adjust to new conditions with sufficient rapidity.

\section{AFTER THE THRESHOLD HAS BEEN CROSSED}

Ecological disequilibrium that follows the crossing of a threshold might well cause political disequilibrium as well. Conditions are likely to be markedly less favorable than they formerly were. Additionally, many areas already exist where political disequilibrium might be further exacerbated by ecological disequilibrium. Anarchy resulting from either ecological or political disequilibrium might well preclude a systematic, orderly, reasoned response to these new conditions. If humans survive such circumstances, it will probably be as a series of petty fiefdoms or tribal units. If some degree of societal integrity remains, there are a large number of possible outcomes, for which a few illustrative scenarios follow.

Scenario \#1. An important ecological threshold is crossed but the system's integrity is not destroyed and sufficient ecological resiliency remains to enable a return to some semblance of earlier conditions

The assumption in this scenario is that the threshold is crossed, but there is a realization of the crossing before ecological integrity has been destroyed or severely impaired. Corrective actions are taken to remove anthropogenic stress, permitting the system to return to some degree of its predisturbance state. An example of this scenario is the work on the Kissimmee River in Florida, which was thrown into ecological disequilibrium by the construction of a canal by the U.S. Army Corps of Engineers. As noted by the National Research Council (1992), the ecological consequences of the canal construction were severe and apparent to the general public. Demands were made and implemented by the political system to restore at least some of the preexisting ecological conditions. Because prompt remedial action was taken and because recolonizing species were readily available, the restoration and recovery of the system were dramatic and, again, readily apparent to the general public. There are numerous other examples of the recovery and restoration of ecologically damaged regional ecosystems (e.g., Cairns et al. 1977), but, if the anthropogenic stress involves such characteristics as global climate change, these scenarios are unlikely to be common, especially with systems as large as the oceans.

Scenario \#2. An ecological threshold is crossed, resulting in severe disequilibrium conditions followed by a new equilibrium condition substantially different from the one preceding the disturbance

In these cases, ecological restoration to the original equilibrium condition may not be possible for a variety of reasons, including: (1) no adequate sources of recolonizing species, (2) difficulty in restoring antecedent chemical, physical, and habitat conditions, (3) political will for restoration is not sufficiently strong, (4) political will is strong but financial and other resources are inadequate, and (5) exotic species have colonized the disturbed area and have become so firmly established that dislodging them would require an enormous effort and the outcome would be uncertain and problematic. Unless precautionary action is taken early in the $21^{\text {st }}$ century to diminish present rates of biotic impoverishment and ecological damage, this scenario is likely to be the most common one. Ironically, had human society been sufficiently adaptive to build a harmonious relationship with natural systems before irreparable damage occurred, the even more drastic adaptations required after an ecological threshold has been crossed would not be necessary. Preventative adaptation is far more easily implemented than adapting to a new set of equilibrium conditions unlike the ones to which human society has been accustomed for most of human history.

Scenario \#3. A crucial ecological threshold is crossed, reducing the carrying capacity of Earth for humans with a consequent severe and abrupt reduction in population size

The surviving humans selected for their adaptive capabilities and ingenuity might well build a more harmonious relationship with natural systems even in their new, unfamiliar condition

Scenario \#4. A crucial ecological threshold is crossed and the new equilibrium conditions are unsuitable for human habitation

This scenario would resemble, in some ways, the great biological extinctions of the past in which some species survived and speciation resulted in a diverse but different biota over geological time. 


\section{THE PLANETARY CEMETERY}

Although burial places for human remains are becoming increasingly scarce in urban areas, the entire planet is becoming a vast cemetery for nonhuman species without burial markers or even very many mourners. Worse yet, the space occupied for millions of years by myriad life forms is now increasingly covered by human artifacts such as shopping malls and highways. As motorists speed over these sacred grounds, talking on their cell phones and raging at other motorists, it is unlikely that they grieve about the role they have played in the disappearance of these other creatures. If the death penalty for individual humans is increasingly abhorrent in many societies, why is the anthropogenic death sentence for entire species not a colossal sin against life itself? If other species had the power to conduct a Nuremberg trial on planetary death camps for 'lower forms or life' executed with little regret by human society, what would humankind's defense be? It is indeed curious that destruction of the planet's ecological life support system, which supplies essential ecosystem services (Table 1) and is required for sustainable use, receives so little respect. As Wilson (1984) remarks, 'the one

Table 1. Illustrative ecosystem services

1. Capture of solar energy and conversion into biomass that is used for food, building materials and fuel

2. Breakdown of organic wastes, such as sewage, and storage of wastes that cannot be broken down, such as heavy metals

3. Maintenance of a gas balance in the atmosphere that supports human life; absorption and storage of carbon dioxide and release of oxygen for breathable air

4. Regeneration of nutrients in forms essential to plant growth (e.g., nitrogen fixation) and movement of those nutrients

5. Purification of water through decomposition of wastes, regeneration of nutrients, and removal of sediments

6. Storage of freshwater, retention and release of water after rains that provides flood peak reduction, and ground water recharge

7. Distribution of freshwater through rivers

8. Generation, maintenance, and binding of agricultural soils

9. Control of pests by insectivorous birds, insects, bats, and others

10. Pollination of agricultural crops by birds, insects, bats, and others

11. Development and archiving a genetic library for development of new foods, drugs, building materials, and waste treatment processes through both Mendelian genetics and bioengineering

12. Development and archiving a variety of "replacement" species, preventing expected disturbances such as fire, flood, hurricanes, and droughts from disrupting the provision of other ecosystem services

13. Storm protection through physical dispersal of wind and waves by plants

14. Control of both microclimate and macroclimate

15. Recreation and aesthetic satisfaction process now going on that will take millions of years to correct is the loss of genetic and species diversity by thuction of natural habitat. This is the folly ou island in the midst of vast reaches of alien space, it pared the way for self-reflecting human beings.' If assumes that natural capital (i.e., the ecological life hat is necessary to preserve self-maintaining natural "Wher those requiring information on natura et al. (1999) has numerous references and case histo-

Scientific inquiry requires more than a lofty generalzation such as sustainable development or sustainable use of the planet. Moreover, the goals and conditions must be stated for the entire system (Cairns 1997), not ated components such as sustainable agriculabout sustainability, but an organization, tribal unit, or society is needed to practice it.

Paradigm-shifting catastrophes. National Academy of Sciences (NAS) President Bruce Alberts (2000-2001) remarks that a fear of spreading irrationality is perhaps the strongest motivator for the NAS to giving a high priority to what undergraduates understand about science. The NAS has long been active in the battle for a more rational society, and this battle becomes even more important as globalization of human society, its economies, and its effects on natural systems become ever more evident. Just one major inappropriate or irrational decision on such things as global climate change and atmospheric ozone depletion will almost certainly have destabilizing effects on both natural systems and human society. Some months ago, two momentous events were given scant attention in the news media. The first was the discovery by an ice breaking Russian cruise ship steaming towards the North Pole during the Arctic summer that miles of open water has replaced previously evident 
thick ice. The presence of sea birds, where none have been seen before, was an indication that this open water had existed for more than a day or two. The second event, at the opposite end of Earth in Antarctica, confirmed that the hole in the ozone layer over the Antarctic continues to grow and is now three times the size of the United States. The casual way in which both events were treated by the new media suggests that nothing short of a major ecological/societal catastrophe will cause a paradigm shift into a series of sustainable use of the planet practices. A catastrophe of this size could easily be irreversible. Hardin (1998) has superbly addressed the task of overcoming denial of the tough ecological issues of population, economics, and ethics. A central issue is the consequences of total freedom in a world of limits. Hardin further notes that, in the arrangements of nature, freedom is relegated to an operational position that is secondary in importance to survival and concludes that, in a competitive world of limited resources, total freedom of individual action is intolerable. Hardin (1998) remarks that scientists favor consequential ethics, which is less interested in historical origins and more concerned with the future consequences of present acts. Almost certainly, a major ecological/societal catastrophe would produce a system of consequential ethics. Motivational ethics might still triumph because, in times of societal disequilibrium, a return to past conditions can be very attractive.

Motivational ethics will probably create still more catastrophes and, ultimately, the survivors, if any, will turn to consequential ethics. It is interesting to speculate on what consequential ethics might emerge in environmental politics, if taken in a sustainability context.

1. The free market as now defined will almost certainly cease to exist, as will individual freedom as now interpreted.

2. Any actions seriously damaging the planet's ecological life support system will result in drastic consequences for the individuals or organizations causing this damage, even if they plead that they were unaware of the outcome of the actions or that there was uncertainty about the outcome.

3. Extravagant, disproportional use of the planet's resources, which is now characteristic of the United States of America and a number of other countries, will be considered aberrant and, therefore, unacceptable behavior.

4. There will be a systematic and orderly allocation of resources between the planet's ecological life support system and human society. It is not clear, and probably it will never be entirely clear, exactly how much space and protection is necessary to preserve ecological integrity and result in self-maintaining ecological life support systems. The precautionary principle advocates erring on the side of prudence or, stated another way, providing more than the minimal amount of resources in the event that the projection of resource needs of natural systems might be short of the mark.

5. The ecological life support system must be given the respect and reverence now accorded the economic system, as a very minimal requirement. The term minimal is deliberately used because the natural systems have been badly abused, and many of their components (i.e., species) have been extirpated. Thus, the ecological systems will be in recovery for at least a century and perhaps longer and, thus, need more protection and respect than if they were robust and normal.

6. It will be essential to improve ecological quality control monitoring to provide early warning signals of impending deleterious effects or the occurrence of deleterious effects or, if not an early warning, detecting the deleterious effects before they have had substantial impact. Ecosystems are dynamic, pulsing systems so both design of the systems and interpretation of the evidence they provide will require much skill and judgment. In the early stages of the development of these monitoring systems, false positives and false negatives will be a major source of irritation. As the systems become more robust, the frequency of false negatives and false positives will diminish but not disappear.

\section{CONCLUSION}

It is easy for most humans to forget that they are only one of millions of species in the ecological 'theater' and have not been on the 'stage' as long as many others, are not as numerous as many others, and do not have the biomass of many other species. As Gorbachev (2001) noted, 'nature will not wait,' and environmental experts warn that many environmentally damaging trends are now too far advanced to achieve real sustainability by means of gradual change; they believe human society has 30 to 40 years in which to act. Time is short, and humankind is already lagging behind. However, the impetus for rapid change in human society is almost always a catastrophe as a consequence of inappropriate practices. The captain of the Titanic could easily have taken precautionary action, which would have made the crossing less memorable but less costly in lives. Human nature is prone to take risks and, when the consequences are literally unimaginable, the risks are taken more lightly than they should be. Nature will persist whatever humans do. It is human society that may not persist whatever humans do!

Acknowledgments. I am indebted to Eva M. Call for tran- 
scribing the dictation of the first draft of this manuscript and to Darla Donald for editorial assistance in preparing the manuscript for publication in this journal and for furnishing valuable assistance in subsequent drafts. The Cairns Foundation paid for processing costs.

\section{LITERATURE CITED}

Alberts B. (2000-2001) From the president, letter to members. Nat. Acad. Sci. 30(3):1

Associated Press (2001a) Bans on road, logging may fall by wayside. Roanoke Times March17:A4

Associated Press (2001b) Bush decides against regulations. Roanoke Times March14:6

Bartlett AA. (1997-98) Reflections on sustainability, population growth, and the environment - revisited. Renew. Resour. J. 15(4):6-23

Brandon K. (1998) Perils to parks: the social context of threats. In K. Brandon, KH. Redford, and S. Sanderson (ed.) Parks in Peril: People, Politics, and Protected Areas, pp. 415-439. Covelo, CA: Island Press

Cairns J., Jr. (1992) The threshold problem in ecotoxicology. Ecotoxicology 1:3-16

Cairns J., Jr. (1994) Ecological restoration: re-examining human society's relationship with natural systems. Abel Wolman Distinguished Lecture. Washington, DC: National Academy of Sciences. $20 \mathrm{pp}$

Cairns J., Jr. (1997) Commentary: Defining goals and conditions for a sustainable world. Environ. Health Persp. 105(11):1164-1170

Cairns J., Jr. (2001) Editorial: Equity, fairness, and the development of a sustainability ethos. Ethics in Science and Environmental Politics (ESEP) Feb 1:1-7

Cairns J., Jr., Dickson, K. L., and Herricks, E. E. (ed.). (1977) Recovery and Restoration of Damaged Ecosystems. Charlottesville, VA: University Press of Virginia. $531 \mathrm{pp}$

Diamond J. (1994) Ecological collapses of ancient civilizations. Bull. Am. Acad. Arts Sci. XLVII:37-59

Diamond J. (1997) Paradises lost. Discover 18:68-78

Dubos R. (1980) The Wooing of Earth. New York: Charles Scribner's Sons. $183 \mathrm{pp}$

Ehrlich P., and Ehrlich, A. (2001). Editorial - The United States: Another leap backward? World-Watch 14(2):5

Gorbachev M. (2001). Editorial - The world: Nature will not wait. World-Watch 14(2):4- 5

Hardin G. (1998) The Ostrich Factor. New York: Oxford University Press. $168 \mathrm{pp}$

Hawken P., Lovins A., and Lovins H., (1999) Natural Capital-

Editorial responsibility: Patricia Ann Fleming,

Omaha, Nebraska, USA

Manuscript (ms) accepted by editor: June 24, 2001 ism: Creating the Next Industrial Revolution. New York: Little, Brown \& Co., Publishers. 378 pp

Hutchinson GE. (1962) The uses of beetles. In The Enchanted Voyage, p. 74. New Haven, CT: Yale University Press

McDonell A., and Vacarin K. (20000 Ejido Cebadillas, imperiled parrots, and a historic conservation partnership. Wild Earth 10(1):55-56

McNeill JR. (2000) Something New Under the Sun: An Environmental History of the Twentieth-Century World. London: W.W. Norton. $421 \mathrm{pp}$

Myers N. with Kent JV. (1998) Perverse Subsidies: Tax \$s Undercutting Our Economies and Environment Alike. Winnipeg, Manitoba, Canada: International Institute for Sustainable Development. $230 \mathrm{pp}$

National Research Council (1992) Restoring Aquatic Ecosystems. Washington, DC: National Academy Press. $552 \mathrm{pp}$

Oates JF. (1999) Myth and Reality in the Rainforest: How Conservation Strategies are Failing in West Africa. Berkeley, CA: University of California Press. $310 \mathrm{pp}$

Odum EP. (2001) The "techno-ecosystem." Bull. Ecol. Soc. Am. 82(2):137-138

Piel G and Segerberg, O., Jr. (ed.). (1990) The World of René Dubos: A Collection from His Writings. New York: Henry Hold and Company. $418 \mathrm{pp}$

Postel S. (1999) Pillar of Sand: Can the Irrigation Miracle Last? London: WW. Norton. $312 \mathrm{pp}$

Salafsky N, Dugelby BL, Terborgh, JW (1993) Can extractive reserves save the rainforest? An ecological and socioeconomic comparison or non-timber forest product extraction systems in Petén, Guatemala and West Kalimantan, Indonesia. Conserv. Biol. 7:39-52

Schettler T., Solomon G., Valenti M., and Huddle A. (1999) Generations at Risk: Reproductive Health and the Environment. Boston, MA: MIT Press. $417 \mathrm{pp}$

Schettler T., Stein J., Reich F., and Valenti M. (2000). In Harm's Way: Toxic Threats to Child Development. Boston, MA: Greater Boston Physicians for Social Responsibility. $140 \mathrm{pp}$

Soulé M. E. (2001) Does sustainable development help nature? Wild Earth 10(4):56-64

Terborgh J. (1999) Requiem for Nature. Covelo, CA: Island Press. $248 \mathrm{pp}$

Wilson EO. (1984) Biophilia: The Human Bond with Other Species. Cambridge, MA: Harvard University Press. 157 $\mathrm{pp}$

Wire Reports. (2001). EPA chief to ease gas standards. Roanoke Times March17:A3

MS received at Headquarters: June 25, 2001

MS published on the web: June 26, 2001 
